\title{
Hydroinformatics education - the Water Informatics in Science and Engineering (WISE) Centre for Doctoral Training
}

\author{
Thorsten Wagener ${ }^{1,2,9}$, Dragan Savic ${ }^{3,4}$, David Butler ${ }^{4}$, Reza Ahmadian ${ }^{5}$, Tom Arnot ${ }^{6}$, Jonathan Dawes ${ }^{7}$, \\ Slobodan Djordjevic ${ }^{4}$, Roger Falconer ${ }^{5}$, Raziyeh Farmani ${ }^{4}$, Debbie Ford ${ }^{4}$, Jan Hofman ${ }^{3,6}$, Zoran Kapelan ${ }^{4,8}$, \\ Shunqi Pan ${ }^{5}$, and Ross Woods ${ }^{1,2}$ \\ ${ }^{1}$ Department of Civil Engineering, University of Bristol, Bristol, UK \\ ${ }^{2}$ Cabot Institute, University of Bristol, Bristol, UK \\ ${ }^{3}$ KWR Water Research Institute, Nieuwegein, the Netherlands \\ ${ }^{4}$ Centre for Water Systems, College of Engineering, Mathematics and Physical Sciences, University of Exeter, Exeter, UK \\ ${ }^{5}$ Hydro-environmental Research Centre, School of Engineering, Cardiff University, Cardiff, UK \\ ${ }^{6}$ Water Innovation and Research Centre, Department of Chemical Engineering, University of Bath, Bath, UK \\ ${ }^{7}$ Institute for Mathematical Innovation and Department of Mathematical Sciences, University of Bath, Bath, UK \\ ${ }^{8}$ Department of Water Management, Delft University of Technology, Delft, the Netherlands \\ ${ }^{9}$ Institute of Environmental Science and Geography, University of Potsdam, Potsdam, Germany
}

Correspondence: Thorsten Wagener (thorsten.wagener@bristol.ac.uk)

Received: 15 September 2020 - Discussion started: 5 October 2020

Revised: 17 April 2021 - Accepted: 23 April 2021 - Published: 20 May 2021

\begin{abstract}
The Water Informatics in Science and Engineering Centre for Doctoral Training (WISE CDT) offers a postgraduate programme that fosters enhanced levels of innovation and collaboration by training a cohort of engineers and scientists at the boundary of water informatics, science and engineering. The WISE CDT was established in 2014 with funding from the UK Engineering and Physical Sciences Research Council (EPSRC) amongst the universities of Bath, Bristol, Cardiff and Exeter. The WISE CDT will ultimately graduate over $80 \mathrm{PhD}$ candidates trained in a non-traditional 4-year UK doctoral programme that integrates teaching and research elements in close collaboration with a range of industrial partners. WISE focuses on cohort-based education and equips the $\mathrm{PhD}$ candidates with a wide range of skills developed through workshops and other activities to maximise candidate abilities and experiences. We discuss the need for, the structure and results of the WISE CDT, which has been ongoing from 2013-2022 (final year of graduation). We conclude with lessons learned and an outlook for $\mathrm{PhD}$ training, based on our experience with this programme.
\end{abstract}

\section{Introduction}

The global water cycle consists of a complex web of interacting physical, biogeochemical, ecological and human systems (Gleeson et al., 2020). Management of this complex cycle has been practised for decades, but new challenges lie ahead due to climate change, growing population pressure, increasing urbanisation and other human-caused environmental disturbances. These challenges can only be addressed through fundamental changes in how we interact with our environment, both in perspective and in practice. The recent focus on the role of water security in addressing ecosystem services and sustainability has further emphasised the need for new approaches to achieve this dual goal (UNEP, 2009, 2011, 2017). In the UK, the government's 25-year Environment Plan (2018) clearly signals the importance and value of the environment, including "reducing our carbon emissions and building resilience against the extreme weather associated with climate change." Infrastructure is considered equally important as evidenced by the UK National Infrastructure Assessment (2018), which regards water and waste infrastructure as being essential for health and wellbeing, environmental sustainability, and economic stability, and which 
points to investment of GBP 44 billion in the water sector. At the European level, the EC sponsored ICT4Water cluster has published its Digital Single Market for Water Services Action Plan (2018). Supporting these efforts in turn requires new, whole-system, multi-faceted, data-intensive, interdisciplinary approaches to research, training and innovation - approaches which take advantage of the information explosion and leading-edge technologies of the 21st century (Blöschl et al., 2012; Ceola et al., 2015; Habib et al., 2012; Jonker et al., 2012; King et al., 2012; Montanari et al., 2013; Ruddell and Wagener, 2013; Seibert et al., 2013; Thompson et al., 2012; Wagener et al., 2010, 2012).

As the capabilities of digital devices soar and their prices plummet, sensors are providing greater amounts of information than ever, at lower costs and with greater reliability than previously possible (Mao et al., 2018). Opportunities for real-time monitoring and management are increasing dramatically; so is access to far more powerful information and communication technology (ICT) tools and devices (ICT4Water cluster, 2018). These tools enable "people as sensors" (crowdsourcing, citizen science), bringing together the skills of humans to observe and interpret with the interconnection of the Internet to enable new types of information to be crowdsourced (Seibert et al., 2019). Combining these trends provides opportunities to address both old and new problems in innovative ways to meet emerging challenges around the water cycle. Globally, it is estimated that savings of USD 7.1 billion to 12.5 billion per annum (SENSUS, 2012) may be realised through the adoption of smart water technologies to minimise operational inefficiencies and to maximise the effectiveness of capital and operational expenditure.

Management of the water cycle, a system characterised by inherent complexity, heterogeneity and uncertainty (not least because of linked social, natural and engineered systems), has already gained from advances in computing, ICT and hydroinformatics resulting in new technologies deployed in engineering practice (Romano et al., 2014). The increasing non-stationarity of the global climate system, and the subsequent implications for the terrestrial water cycle, will significantly change how we approach the problem of longterm planning and of estimating hydrologic design variables (Brown et al., 2015; Milly et al., 2008; Sivapalan and Blöschl, 2015). So, while new data become available as mentioned above, historical data will lose some of their value for long-term analysis, e.g. if catchments have undergone significant land use change, experience more extreme rainfalls than previously recorded or see significantly changed streamflow characteristics due to the building of human infrastructure (Jain and Lall, 2001). Long-term planning in non-stationary systems requires a move away from traditional empirical approaches (widely used in operational engineering hydrology) towards process-based models which are necessarily more complex and require deeper process understanding (Milly et al., 2008; Wagener et al., 2010; Clark et al., 2015; Musolini et al., 2020). Process-based models - increasingly with unprecedented resolutions - will also demand better computational skills of their users to utilise them effectively and thus influence training and education (Hut et al., 2017).

In its 2030 vision document The Value of Water, Water Europe, as the recognised stakeholder platform of the European water sector, promotes a future-proof European model for a water-smart society that requires a paradigm shift in how water is managed (Water Europe, 2020). Bluefield Research assessed that the smart water sector in Europe and the USA is increasing rapidly, estimating that by 2025 it will be worth USD 11 billion and USD 12 billion respectively. A total of $61 \%$ of companies offering digital water solutions in the US market have been founded since the year 2000 (Smart Water Magazine, 2020). The need for this shift, and the tremendous market opportunity it brings, is set against the backdrop of widespread concern for the future of the water sector and its workforce, as for example reported for the UK in a recent employer survey (CIWEM, 2016). The survey found that $81 \%$ of employers saw increased staff turnover and $70 \%$ said that skill shortages had reduced their capacity to deliver projects. Hence the requirement for hybrid skills and expertise in water and informatics will grow with the need for increasingly intelligent systems. New water industry roles such as digital e-service delivery, smart water networks and big data analytics are misaligned with established single-discipline postgraduate programmes and require new hybrid skill sets not normally taught as a package.

For society to take full advantage of leading-edge technologies we need to provide training for hydroinformaticians, i.e. scientists and engineers capable of working at the interface of traditionally separate disciplines of informatics, science, and engineering to manage information and water cycles effectively (Fig. 1) (Popescu et al., 2012; Merwade and Ruddell, 2012; Makropoulos and Savić, 2019). Reports by the Council for Science and Technology (CST, 2009), the UK Royal Academy of Engineering (RAE, 2012), and the UK Institution of Civil Engineers (ICE, 2012) have highlighted a particular shortage of engineers and scientists in industries of national importance for the UK, such as energy, water, sanitation, communications and IT systems. In response to the projected skill shortage in the IT sector in $\mathrm{Eu}-$ rope, the European Commission has launched a grand coalition to tackle this shortage (CEDEFOP, 2018). It is difficult to see how the need for skilled engineers working at the interface of IT with water science and engineering can be met by IT graduates alone - who would also have to be educated in water processes subsequent to their IT training. We rather need to train scientists and engineers who can work at the interface of traditionally separate informatics, science and engineering disciplines to fill these hybrid job roles.

The Water Informatics in Science and Engineering Centre for Doctoral Training (WISE CDT, http://wisecdt.org.uk/, last access: 17 May 2021) aims to fill the skills gap discussed above by offering a postgraduate programme that fosters en- 


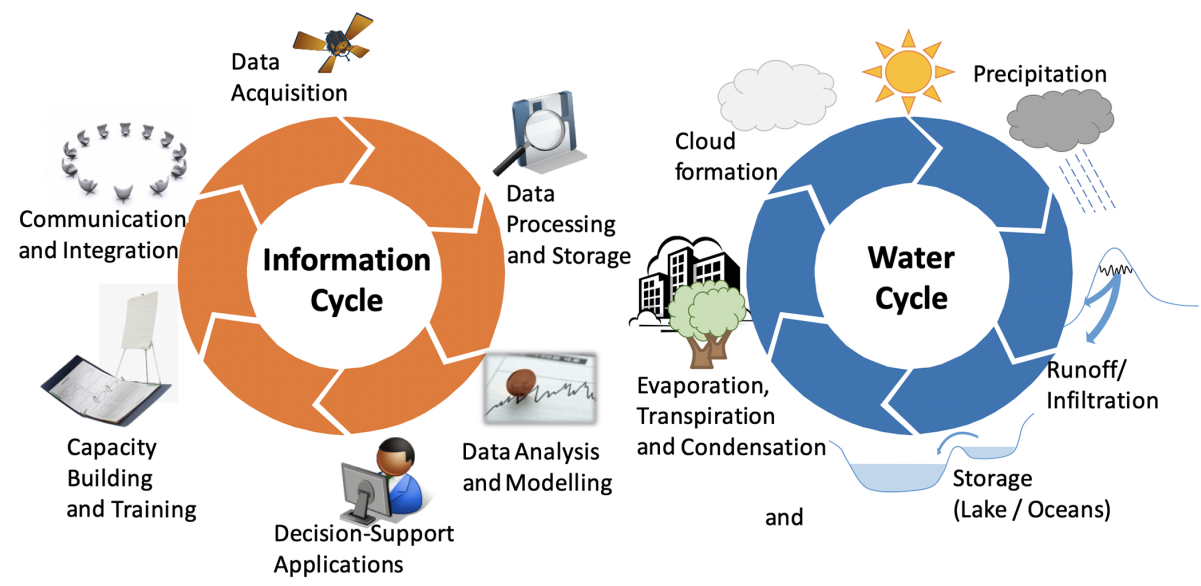

Figure 1. Information and water cycles.

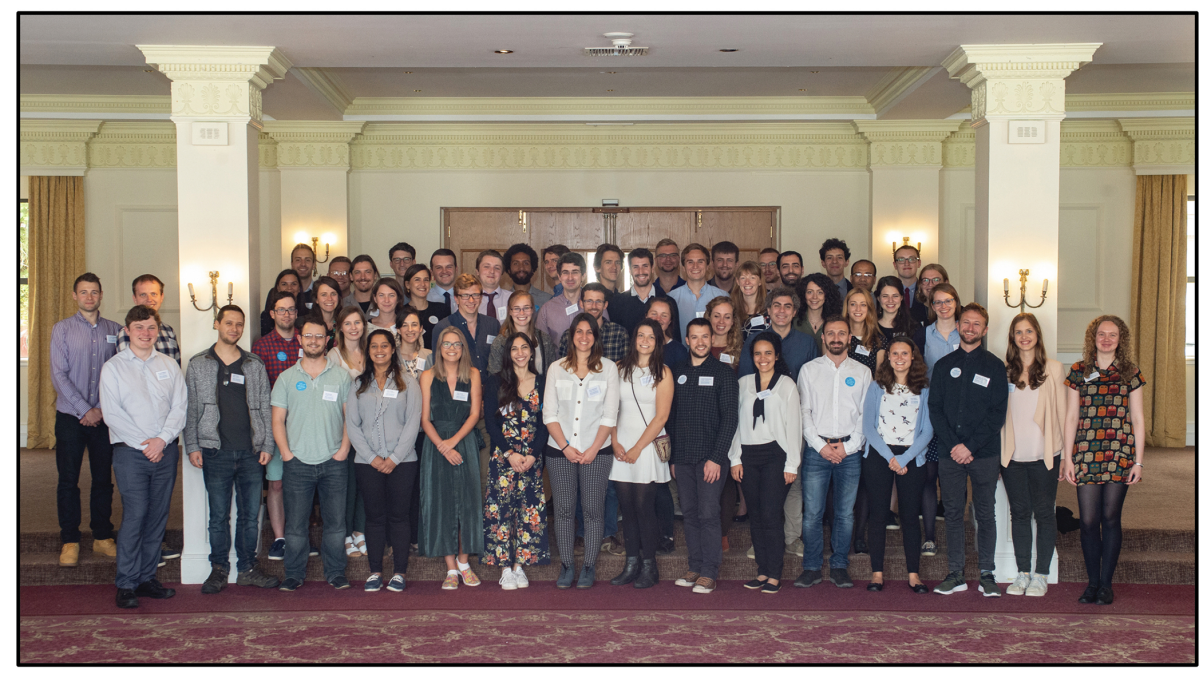

Figure 2. WISE CDT PhD students (summer school in Torquay, UK, 2019; photo credit @ Steven Haywood 2019).

hanced levels of innovation and collaboration to train a cohort of engineers and scientists at the boundary of water informatics, science and engineering. Disciplinary breadth, a focus on $\mathrm{PhD}$ candidate cohort experience and collaborative effort (not least between four research-intensive UK universities in delivering the programme) are its key novel features. The WISE CDT was established in 2014 with funding from the UK Engineering and Physical Sciences Research Council (EPSRC) and led by the University of Exeter in partnership with the universities of Bath, Bristol and Cardiff. The WISE CDT inducted its first cohort of PhD candidates in October 2014, and thus far it has recruited 84 candidates and graduated 26 (as of April 2021). The final group of candidates was recruited in 2018 and is expected to graduate in 2022 (Fig. 2). The initial principal investigator was Professor Dragan Savic (2014-2018), and now it is Professor David Butler. Here we describe the programme, show some selected educational elements and discuss what the WISE CDT has achieved so far.

\section{The WISE CDT training approach}

There is growing evidence that producing highly skilled researchers and future leaders requires doctoral supervisory teams to support (a) candidates' specialist disciplinary development and (b) their wider skills development (Roberts, 2002; Buckley et al., 2009; Brodin and Avery, 2020). Such a "T-shaped competency profile" of broad general and in-depth disciplinary skills has been identified as crucial for future water professionals (Uhlenbrook and de Jong, 2012). The WISE CDT programme addresses both sets of skills through

i. candidates participating in a two-semester WISE CDT postgraduate school involving both broader disciplinary and wider research methodology training, thereby in- 
Table 1. WISE CDT programme components.

\begin{tabular}{lllll}
\hline & Year 1 & Year 2 & Year 3 & Year 4 \\
\hline $\begin{array}{l}\text { Postgraduate } \\
\begin{array}{l}\text { school in water } \\
\text { management and } \\
\text { informatics }\end{array}\end{array}$ & $\begin{array}{l}\text { 120 master's level credits via } \\
\text { a combination of long and thin } \\
\text { and block modules at Exeter } \\
\text { (October to May) }\end{array}$ & & \\
\hline $\begin{array}{l}\text { Specialist master's } \\
\text { level modules }\end{array}$ & Specialist modules based on the agreed research topic and in & & \\
\hline $\begin{array}{l}\text { Transferable and } \\
\text { leadership skills }\end{array}$ & $\begin{array}{l}\text { Skills training at Exeter } \\
\text { (during the postgraduate }\end{array}$ & $\begin{array}{l}\text { At Bristol } \\
\text { (1 week) }\end{array}$ & $\begin{array}{l}\text { At Cardiff } \\
\text { (1 week) }\end{array}$ & $\begin{array}{l}\text { At Bath } \\
\text { (1 week) }\end{array}$ \\
\hline $\begin{array}{l}\text { Research project } \\
+ \text { thesis writing }\end{array}$ & From June to September & All year & All year & All year \\
\hline
\end{tabular}

creasing candidates' research skills and knowledge base while enhancing their exposure to interdisciplinary work in ways suitable for careers within or outside academia;

ii. further participation in specialist master's level modules that candidates can attend at WISE CDT partner institutions, after the WISE CDT postgraduate school;

iii. a strategy of "guided freedom" that provides the candidates with opportunities to be active partners in shaping their learning experiences;

iv. formalised career development and placement experience at overseas academic or industry partners; and

v. further transferable and leadership skills development that enhances candidates' career and project management skills, ensuring they make a successful transition to their career of choice.

\subsection{WISE CDT postgraduate school in water management and informatics}

Each WISE CDT PhD lasts 4 years (Table 1): the first two semesters (October to May) are allocated to a WISE CDT postgraduate school in water management and informatics (run at the University of Exeter and including lectures from staff at Cardiff, Bath, and Bristol universities as well as our industrial and international partners). The residential school ensures that a functioning cohort of WISE CDT PhD candidates is immediately established, thereby reducing the risk of attrition due to the feeling of not belonging to an academic community (McAlpine et al., 2009) or due to social isolation (Ali and Kohun, 2007). The structured approach to the WISE CDT cohort/community development applies for the duration of the programme involving the four-stage framework for dealing with social isolation developed by Ali and Kohun (2007). The WISE CDT framework addresses (i) pre-admission to enrolment (orientation, administrative liaison, formal social and induction events), (ii) first year (integration, cohort approach, ice-breaking, buddy system, research proposal development, supervisor selection), (iii) second year through to thesis writing (collaborative model, topic presentation and feedback, summer school, transferable/leadership skills), and (iv) thesis stage (structure for the thesis, collaborative model, face-to-face communication).

As the programme is aimed at a diverse set of graduates from engineering, environmental science, geographical science, physics, mathematics, and computer science, candidates devote the first two semesters to taking an appropriate set of existing postgraduate-level modules at Exeter to cover their knowledge gaps as well as to advance their skills in water processes and informatics. The cohort's basic programming skill is brought to a similar level (with some candidates advancing clearly above this level) by a learningby-doing model with a software development project related to one of the water cycle themes (Fig. 1). The project and module offerings are augmented by specialist ICT modules, by staff from partner institutions (both national and international), and industry, including modules on, for example, software development, cloud computing, object-oriented programming and cyberinfrastructure. This training includes a $3 \mathrm{~d}$ intensive training course, which has been arranged for each of the cohorts early in the WISE CDT postgraduate school, to provide researchers with practical experience of software development techniques. The IT focused teaching components are complemented by "water knowledge" components in which each partner institution trains candidates in their specific area of strength (Exeter: urban drainage, Bath: wastewater treatment, Bristol: hydrology, Cardiff: hydraulics).

This programme of training ensures that all candidates gain a solid understanding of water informatics, of knowledge across water topics, and of wider research methodology before they develop and commence on their $\mathrm{PhD}$ research 
project. The postgraduate school programme comprises eight taught master's level modules, worth a total of 120 credits. These include

- Hydroinformatics Tools,

- Urban Drainage and Wastewater Management,

- Water Supply and Distribution Management,

- Environmental and Computational Hydraulics,

- Computational Hydrology,

- Mathematical Modelling of Wastewater Treatment Processes,

- Programming for Engineering, and

- Research Methodology.

WISE CDT candidates across the cohorts appreciated the opportunity to attend a first year of courses, which is uncommon for a $\mathrm{PhD}$ programme in the $\mathrm{UK}$, where traditional $\mathrm{PhDs}$ are typically based on individual research only. We selected some candidate quotes from our regular surveys (discussed further below) to highlight this aspect.

I have found that, as my $\mathrm{PhD}$ research has developed, the modules from the Postgraduate School have become very useful. A good example of this is computer programming and coding, which now forms a substantial part of my research, despite me knowing very little about it before starting the programme (Candidate James Webber, University of Exeter, Cohort 1).

The postgraduate school in Exeter helped to broaden my knowledge of the water world and gave me confidence to get out of my comfort zone and develop my $\mathrm{PhD}$ work in a direction that straddles multiple engineering disciplines (Olivia Bailey, University of Bath, Cohort 2).

I am currently in my first year of the WISE CDT programme, attending the Postgraduate School at the University of Exeter. This year has allowed me to receive an overview of the different research areas of the four partner universities, as well as giving me the opportunity to explore new ideas, methodologies and inspirations which have helped shape my research project. In addition to the scientific knowledge that I have gained, I have also become an integral member of my cohort group. Coming from a different country meant that I faced many challenges regarding language, culture, regulations, etc., but the support of my fellow peers, better known as my "WISE-Family", has helped me to overcome these challenges, for which I am very grateful. Ultimately, the WISE CDT has been a great opportunity for me to undertake my $\mathrm{PhD}$ adventure in the UK (Stephanie Mueller, Cardiff University, Cohort 4).

Unlike other doctoral programmes, the WISE CDT offers the opportunity to take part in a wide range of courses and activities such as transferable skills modules and research seminars, which have helped me to gain valuable skills, explore new ideas and methodologies, and meet new people from both industry and other academic institutions. Finally, the cohort-based structure of this programme was undoubtedly one of the most appealing points. Gathering people with different academic backgrounds has provided us with an opportunity to support each other and develop a comradeship throughout our first year. In particular, as I come from a different country I have had to deal with many new things and my peers have provided me with lots of support, helping me to make this transition much easier (Georgios Sarailidis, University of Bristol, Cohort 5).

Further familiarisation with facilities and potential supervisors from the other three universities during the postgraduate school is ensured by seminar visits arranged at each of the partner institutions. Candidates pursue further specialist skills training available at partner institutions after the postgraduate school. These taught components in years 2-4 (selected based on candidate background and intended specialisation) are chosen from postgraduate-level modules offered by the partner institutions in agreement with supervisors.

\subsection{Transferable skills and leadership programme}

The need for improvement in the development of research careers and training in transferable skills was highlighted in Sir Gareth Roberts' report (Roberts, 2002), which led to new funding for generic skills training and further calls for the development of research skills at both the $\mathrm{PhD}$ and postdoctoral career stages in the UK (RCUK, 2010). The WISE CDT offers extensive and structured provision of transferable and leadership skills through the Transferable Skills and Leadership Programme arranged during the WISE CDT postgraduate school and over the subsequent years for each cohort in multi-day blocks, as listed in Table 1. In year 1 (in Exeter), the programme concentrates on the acquisition of a deeper understanding of the research process and methodology, together with project management for researchers, personal effectiveness, communication skills (both written and oral), relationship between science and society, and introduction to ethics. In subsequent years all candidates attend residential programmes which cover a wide range of areas including year 2 (in Bristol) - preparation and delivery of conference talks and posters (including an external consultant teaching 
a $1 \mathrm{~d}$ workshop titled "with confidence at conferences") and writing and refereeing of journal articles; year 3 (in Cardiff) management and team working skills, professional etiquette, planning and writing a thesis, thinking of one's career, and entrepreneurship and leadership skills; year 4 (in Bath) viva preparation, strategic problem formulation, knowledge exchange and research exploitation, and early career development.

\subsection{WISE CDT summer school}

An annual week-long residential summer school (incorporating a mini conference) provides an opportunity for supervisors and $\mathrm{PhD}$ candidates from all cohorts and diverse disciplinary backgrounds to share their experiences of working on water-informatics-related projects while networking with other staff and candidates (Fig. 3). They are joined by the strategic advisory board, which includes representatives from key stakeholders (e.g. water companies, government agencies, and consultancies), for part of the week. The summer school serves candidates from years 1 to 4 , with emphasis on encouraging discussion and exchange of ideas across disciplinary boundaries (i.e. natural sciences, engineering, humanities and social sciences). Each summer school is organised around a central water informatics challenge, including (1) "Water Hackathons" - an intensive competition of brainstorming and computer programming that draws together the talent and creativity of participants, who were tasked with identifying water sector challenges and developing mobile phone app ideas to address these; (2) developing a proposal to improve our global understanding of a relevant water issues for submission to a fictional international agency; (3) a water game, where candidates produced a water-themed board game - the winning group created an educational game, named "Hydropolis", which focused on water management challenges faced by developing cities; (4) water security challenge, where candidates were asked to develop a business plan for a UK water utility which focussed on addressing long-term water security; (5) design of flood defences in Devon, where candidates worked with a local authority and the Environment Agency to propose innovative flood defence approaches in the Torbay area (UK) in the context of climate change; and (6) a currently planned event - a specialist in the design of infographics has been hired to run a workshop for the $\mathrm{PhD}$ candidates, to be followed by group projects where candidate teams are asked to design water infographics.

Workshops, mini group projects and networking sessions during the summer school have been organised, not only to address the main summer school topic, but also to help in developing both specific and transferable research skills, and generic skills, to prepare participants for future careers both inside and outside of academia. The participants meet every morning with internationally recognised academics (e.g. Elena Toth, University of Bologna; Patrick Reed, Cor- nell University) and leading industrial experts (including those from non-technical disciplines, e.g. business, ethics, law, psychology, marketing) to discuss their ideas and receive feedback. The afternoon is reserved for development activities. The summer school's main activity finishes with participants pitching their ideas to a "Dragon's Den" style panel of academic and industry representatives that judge the outcomes and award prizes to the best ideas. Dragon's Den is a British TV series where entrepreneurs attempt to sell their business ideas. During the summer school, a $1 \mathrm{~d}$ mini conference/symposium is organised to allow participants to present their research ideas and progress on their $\mathrm{PhD}$ projects. These activities again involve outside agencies to help both candidates and academics embed creative problem-solving approaches within the CDT. The summer school is also used for a $\mathrm{PhD}$ progress monitoring meeting (performed by the programme management group - PMG), where progression to the next year of the research programme depends on satisfactory performance in the previous year. An annual written report and a supervisor and mentor meeting report are used to assess the candidate's progress fairly and impartially, as well as to give candidates the opportunity to raise any concerns.

\subsection{Supervisory arrangements - guided freedom strategy}

As the primary responsibility for the major aspects of $\mathrm{PhD}$ training rests jointly with the candidate and the supervisors, we proposed a strategy of guided freedom (following ideas by Prof Willem Bouten, University of Amsterdam, based on personal communication with Prof. Jasper Vrugt, UC Irvine) to facilitate the process of empowering the candidates and supervisory teams to create a successful doctoral training experience. We implemented the strategy in two stages, each involving a number of activities.

The first stage, which takes place during the postgraduate school (year 1 of the $\mathrm{PhD}$ programme), involves the following activities: (i) a biweekly (every 2 weeks) candidate-led journal paper review seminar, (ii) the first summer school (including candidate project discussions) and (iii) research proposal development. Paper review seminars initially involve academic members of staff in guiding paper selection (across the topics covered by the WISE CDT programme) and critical review, but with responsibilities gradually passed onto the candidate cohort itself. An activity, in which the firstyear candidates discuss, develop and choose three research topic areas in agreement with potential academic supervisors and partners, runs throughout the year. Candidate choices are then reviewed, one topical area is selected and candidatesupervisor connections are established, with the research proposal being presented at the summer school event. During the first stage, the candidates also participate in weekly cohort seminars/meetings linked to the postgraduate school. The first stage of the programme finishes with research proposal presentations and allocation of the supervisory teams. The 


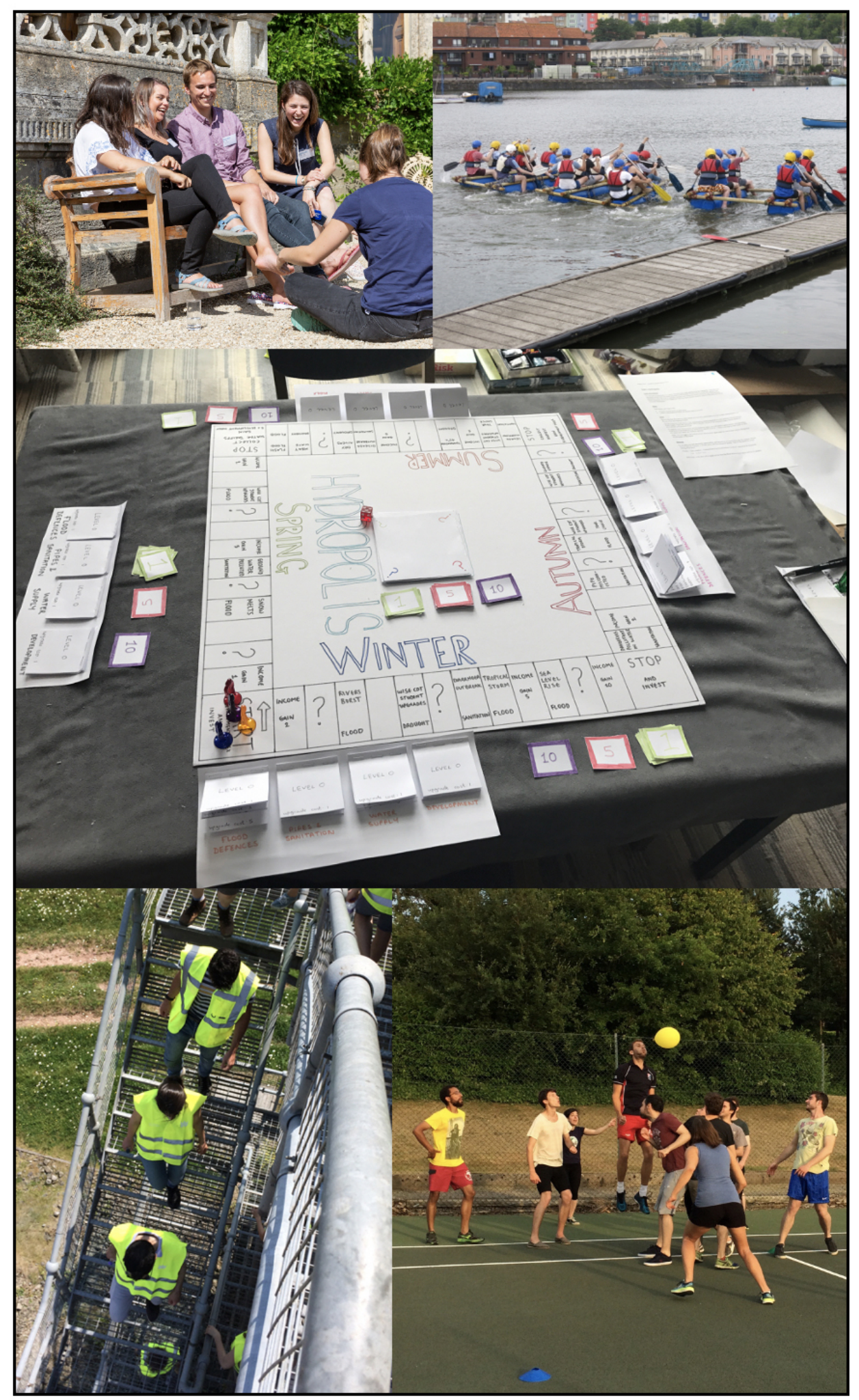

Figure 3. Examples of summer school activities (photo credits: top left @ Tim Gander 2018; bottom left and right @ Lina Stein 2017). 
time between the summer school and the beginning of year 2 is focused on refining the research proposal and planning.

Each supervisory team involves a primary project supervisor and a second supervisor at the institution where candidates are registered. The supervisory team also includes a mentor who can make an objective assessment of the candidate's progress, provide pastoral support, and monitor the all-important working relationship between the (primary) supervisor and candidate. We encourage that, in addition to the supervisory team at the primary institution, candidates also have a supervisor at one of the other institutions who provides a complementary skill set or expertise. In addition to enhancing the candidate's training, this interaction also promotes cross-institutional research. The supervisory team is completed by an industrial advisor in cases where the project is co-funded by a sponsoring organisation. We also encourage supervisory teams where early career academic colleagues are working alongside experienced $\mathrm{PhD}$ supervisors (the early career academic is normally the lead supervisor). During the second stage of their PhD, CDT candidates have regular meetings with the supervisory team at the institution where they are registered (commonly every 1-2 weeks), while also participating in the regular research group meetings (organised by the well-established institutional research groups).

\subsection{WISE CDT management structure}

Management of the WISE CDT is structured as follows. Dayto-day management of the WISE CDT is provided by the lead principal investigator (PI) and the WISE postgraduate school manager at the University of Exeter (the latter is an academic staff member with $50 \%$ time availability), with support of a full-time administrative position. Each partner university has a co-director (Co-D) and a co-investigator (Co-I) as a local management team (10\% time commitment), supported by a part-time administrator ( $20 \%$ time commitment). We found that two academic staff members per university (Co$\mathrm{D}$ and Co-I) are necessary so that regular meeting participation and continuous candidate support can be assured. The PI, Co-Ds and Co-Is make up the programme management group (PMG), which meets once every 3 months to review progress, consult with candidates and make CDT management decisions. A strategic advisory board meets annually to receive reports on all aspects of the CDT operation and provide external input and recommendations.

\section{Candidate experience}

A key aspect of any CDT is to develop and embed ways of working that enhance the research candidate experience with the goal of graduating well-balanced and better-prepared $\mathrm{PhD}$ candidates. To strengthen the feeling of belonging to the WISE CDT academic community and to reduce social iso- lation, the WISE CDT programme established peer-support groups (a buddy scheme), whereby all incoming first-year candidates are assigned to a second-, third- or final-year $\mathrm{PhD}$ candidate at Exeter who has volunteered to become a "buddy". This effort is followed by a similar system being established for them when they move to the university where they are registered for the remainder of the programme. All first-year PhDs are invited to meet their buddies at the beginning of the WISE CDT postgraduate school. There is no pressure to do so, but candidates are regularly made aware that there is someone who they can contact to ask for advice.

\subsection{Candidate participation and feedback}

We regularly gather feedback from our candidates, through surveys, individual feedback or via the cohort representatives. The surveys would cover the following:

- end of year 1 - postgraduate school review meeting and face-to-face feedback to centre manager and programme director;

- Transferable Skills and Leadership module evaluation forms;

- annual progress review "happiness index"; and

- end-of-programme candidate experience survey.

Everything is reported to the PMG (directors and co-Is) and discussed at their quarterly meetings. Data from the happiness index and candidate experience surveys are also reported to the external strategic advisory board. In addition, we informally expect candidate representatives to survey their cohort to feed in ideas, comments and criticism to each quarterly PMG meeting.

Each cohort of $\mathrm{PhD}$ candidates elects a representative during their first year on the programme. Representatives actively contribute to PMG meetings to feed in comments from their peers, to participate in discussions, and to make recommendations and bring in ideas. They are present for all open business agenda items (i.e. only excluding closed business items where CDT financial and individual candidate matters are discussed), receive minutes of all meetings and contribute agenda items for discussion. Each cohort maintains a closed social media group to share feedback and provide peer support. Every year, the WISE CDT uses the candidate feedback to trigger actions and various modifications of the programme.

In response to a request from the CDT strategic advisory board, a happiness index question was incorporated into candidates' 2018-2019 annual progress review forms. This question asked candidates to rate their general happiness in their $\mathrm{PhD}$ on a scale from 1-5 (from "very unhappy" to "very happy"). A total of 63 current candidates across cohorts 2-5 answered this question, with $70 \%$ overall assessing themselves to be either "happy" or "very happy". There appeared 
to be no correlation between happiness rating and progress, although generally each cohort was "happier" than the previous one. We considered this could relate to the ongoing improvements being made to the programme but might also indicate the increasing pressures felt when nearing completion of a PhD. The CDT will continue to use the happiness index question in future years, enabling valuable longitudinal studies. The experience gained through running the CDT has provided insight as to the best scheduling of events or inclusion of new content or activities. Comprehensive candidate feedback data complement this by identifying the points at which declining satisfaction is more likely, enabling proactive interventions to be made. We also share the CDT's candidate experience data (in anonymised form) and other metrics amongst the partner organisations so that good practice is disseminated.

A candidate experience survey was undertaken for our first cohort on completion of their PhD programme. This survey asked candidates a range of questions about their experience of the CDT, aiming to find out what had been valuable, what could be improved and what difference the WISE CDT had made to them. The survey questions incorporated ratings from 1-5 (from "very poor" to "excellent") plus free text comment fields. While the sample size was small, everyone completed and returned the feedback form. Candidates rated the CDT experience overall as "good", with a mean score of 4.25 out of 5 . Most frequently mentioned as the best elements were the cohort experience and support and friendships gained, the opportunity for a funded research visit, and the opportunity throughout the programme to present work and engage with other researchers. These results are pleasing, as they represent the areas not generally available on a standard PhD programme. The most frequently cited areas for improvement were the following. (1) Rethink the postgraduate school - we went from six compulsory and two optional modules to eight compulsory modules which reduced candidate options but was required due to universitywide changes. We also went from long and thin modules, over a full semester, to short and thick modules, over a few weeks. We further tried to help candidates who came into the programme with less quantitative skills to catch up before the actual programme started. (2) Develop a unified approach across the four universities (e.g. registration periods, $\mathrm{PhD}$ thesis submission, extension requests) - this was difficult to adjust given that these administrative processes were largely out of our control, though communication was improved. (3) Allow for more interaction between the four universities, including both candidates and academics (e.g. joint supervision, inter-disciplinary events, data/software sharing) - this interaction was expanded as WISE grew. This exit survey will be undertaken annually as each cohort completes their programme.

Throughout the CDT, candidate feedback has contributed to the evolution of the CDT structure. The main actions un- dertaken in response to constructive criticism from candidates are the following:

- enhanced candidate support/administrative support;

- obtaining Chartered Institution of Water and Environmental Management (CIWEM) accreditation to meet the needs of candidates without a formal engineering background (they found that this will help their employability with engineering companies);

- amendments to content and scheduling of the taught components of the postgraduate school;

- enhancements to transferable skills modules, e.g. viva preparation, career guidance;

- broadening the industry day focus/range of guests to cover the breadth of candidates' research interests;

- website enhancements - including a secure library of CDT templates/guidance;

- ongoing engagement with alumni, including in CDT events, e.g. talks to current candidates;

- involving candidates actively in planning of CDT events.

\subsection{Industry engagement and professional accreditation}

The WISE CDT aims to develop PhD graduates who may progress to academic, industry, regulatory, practitioner or research institutions. In this respect exposure to real industry challenges and projects, and the networking and career development opportunities that arise from engagement with industry, are highly valuable and necessary components of the training programme delivered by the CDT. To deliver this aspect there are various components of the programme with an industry focus: (i) a series of seminars and invited lectures from industry and water-related stakeholders during the postgraduate school in Exeter; (ii) an annual WISE CDT industry day where the candidates present their project proposals/results to date to water industry and practitioner stakeholders via a poster and networking session; (iii) engagement with our strategic advisory board (SAB) via a poster competition (judged by the $\mathrm{SAB}$ ) held during the annual summer school; (iv) engagement with professional organisations such as the Chartered Institution of Water and Environmental Management (CIWEM), the Institute of Water (IoW), British Hydrological Society (BHS), UK Water Industry Research (UKWIR), International Association for HydroEnvironment Engineering and Research (IAHR), and the International Water Association (IWA) as relevant. Additionally, many of the $\mathrm{PhD}$ projects within the WISE CDT programme are co-developed by the candidates and their supervisor teams with industry and/or practitioner partners, ensuring a route to impact and adding real-world relevance to the 


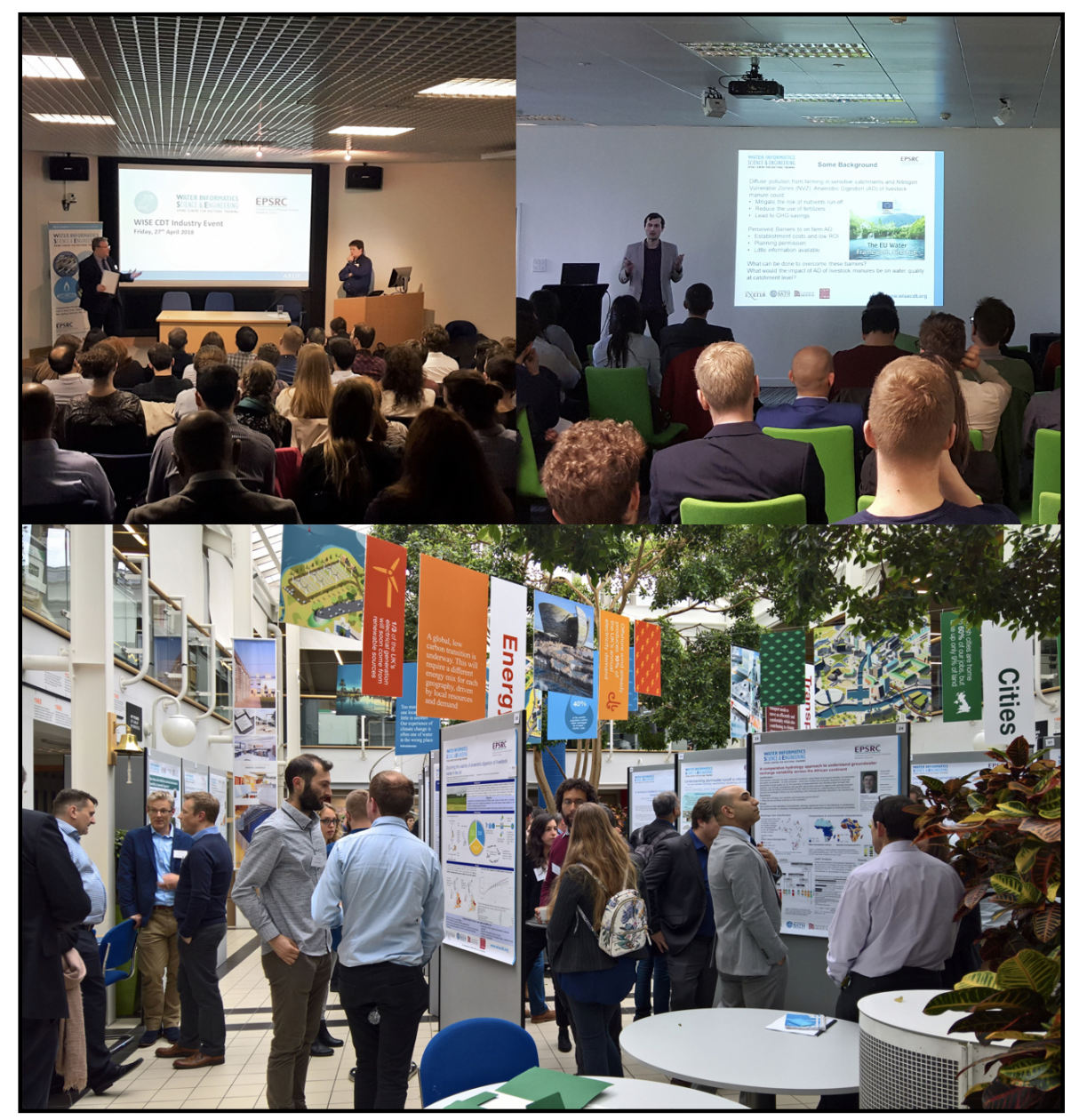

Figure 4. We have run WISE CDT industry days with Atkins in 2016, HR Wallingford in 2017, Arup in 2018 and jointly with the Wet Networks event series in 2020 (photo credits: (C) Tom Arnot).

project when it is delivered. Industrial partners have found this level of interaction highly beneficial, e.g. Dan Green, head of sustainability and innovation at Wessex Water, said "Wessex Water is seeing the emergence of skills and knowledge gaps in common with other companies in the water sector.... The WISE CDT helps address these gaps by providing leading interdisciplinary training across the subject areas of water engineering and informatics which are vital for the future of this industry and highly pertinent to our company". Industry interest has led to jointly funded projects operating within the WISE CDT, with direct cash funding from industry partners in excess of GBP 0.7 million, and in-kind contributions such as collaborator staff time and advice, invited seminars, site visits, access to stakeholder data, opportunities for in-company or on-site trials, and access to facilities and infrastructure, valued in excess of GBP 2 million.

Industry engagement with the WISE CDT includes the annual WISE CDT industry day, for which the number of UK water industry companies and stakeholders attending has risen from around 20 to about 40 during the last four instal- ments (Fig. 4). For our most recent event in February 2020, run in collaboration with the Wet Networks events which are jointly convened by Arup and WRc, we attracted about 100 attendees for the half-day programme, with roughly $50 \%$ being external guests. Amongst these were water utilities (Bristol Water plc, Dŵr Cymru Welsh Water, Wessex Water), consultants (Arup, Frazer-Nash Consultancy, PA Consulting, RSKW, Sweco, WRc Group), contractors (Jacobs, Mott MacDonald Group, MWH Treatment, Stantec, Wood, WSP), NGOs (Oxfam, RedR UK), supply chain companies (CRALEY Group, DeepRoot, Flow3D, Innovyze, TRE ALTAMIRA), stakeholder organisations (Alliance for Water Stewardship, Water Industry Forum, The UK Water Partnership), and UK Government agencies (Environment Agency, Natural Environment Research Council (NERC)).

WISE also achieved accreditation from the UK Chartered Institution of Water and Environmental Management (CIWEM) programme in June 2018 (https://www.ciwem.org/, last access: 17 May 2021). We pursued accreditation with CIWEM in direct response to candidate feedback as we con- 
sidered that CIWEM accreditation would meet the needs of candidates without an engineering background. This was in fact CIWEM's first accreditation of a PhD course and covers all five cohorts of candidates. Areas of good practice highlighted by the accreditation panel included the relationships with and between candidate cohorts, our industry and practitioner links, and the ability of candidates to draw on academic expertise and facilities across the four universities. Achieving this formal accreditation was important for our candidates because following a CIWEM-accredited programme enhances candidates' career prospects by facilitating their path to chartered engineer status in the UK.

As a student member of CIWEM it is great to see the WISE CDT programme acknowledged as a CIWEM-accredited course. It demonstrates to future employers that CIWEM recognises the course content as relevant to the professional disciplines in the water and environmental management sector, where many of us aspire to end up working (Candidate Laura Wignall, University of Exeter, Cohort 3).

The WISE CDT is well structured to teach the fundamental scientific and practical principles of water engineering design to researchers from multidisciplinary backgrounds. The course is a great gateway to bring new perspectives into environmental engineering - in particular by advancing best practice through linking new computational tools to water management challenges. CIWEM's accreditation of the programme is an excellent benchmark of quality to communicate the benefit of the CDT to future employers and collaborators (Candidate James Webber, University of Exeter, Cohort 1).

\subsection{International research visits}

All WISE CDT candidates are provided with financial support for a 3-month research/industry visit in the UK or abroad (Fig. 5). Most of them spent 3 months with an international partner institution, about a third visited industrial partners while others went to academic institutions, and some visited both. Table 2 shows the diversity of institutions that our candidates visited.

Visiting TU Delft has been the cherry on top of my PhD cake; I feel really proud of what I have achieved. The knowledge and data gained through this visit has really helped to advance the robustness of the last 3 years of work. Of course, it has also been a great opportunity to improve my cycling proficiency! (Olivia Bailey, University of Bath, Cohort 2, visited TU Delft in the Netherlands).
This experience was unique not only in terms of academic enrichment and collaboration but also experiencing the rich and diverse culture of South East Asia (Maria Xenochristou, University of Exeter, Cohort 2, visited the National University of Singapore).

The experience of being able to visit an international university is highly beneficial both practically and personally - you get to develop your skills and knowledge, work with international academics who are experts in your field, and experience a whole new culture at the same time (Stephen Clee, Cardiff University, Cohort 2, visited Hohai University in Nanjing, China).

\subsection{Outreach: The Land of the Summer People art project}

WISE CDT PhD candidates have been involved in a wide range of outreach activities - largely at their home universities after the candidates completed their first year in Exeter. Most outreach activities related to the candidates' research topic, which they only fully engage with in years 2-4 of their PhD. Example outreach activities include the following: (a) Walking with Scientists - Ioanna Stamataki (Bath Cohort 1) led a guided walking tour showcasing Bath's rich science history - as part of FUTURES 2019; Ioanna's talk focused on the historical floods of the River Avon and the applications of using historical data; (b) Tomorrow's Engineers Week 2019 - as part of this initiative, Cardiff candidate Santi Lopez (Cohort 5) volunteered on behalf of ICE Wales to provide engineering team challenges to secondary school students, with the aim of encouraging them to consider a career in engineering; and (c) "Tomorrow" - Swindon's Science Festival; WISE candidates showcased an augmented reality sandbox, developed by the company KeckCAVES and supported by the National Science Foundation in the USA, which allowed the audience to sculpt miniature sand landscapes and generate "clouds" and "rainfall" with their hands. The group also demonstrated the effects of flooding (such as flash flooding from a dam break) and natural disasters (e.g. tsunamis) on different landscapes and their associated engineering mitigation strategies. We generally left organising these activities to the individual $\mathrm{PhD}$ candidates and their supervisors/institutions rather than organising them centrally with an overarching objective in mind. However, one outreach activity was started centrally, and we believe it is worth sharing.

One very worthwhile outreach activity (based on candidate feedback) that took place during the first year of the first $\mathrm{PhD}$ cohort was the project The Land of the Summer People (https://thelandofthesummerpeople.org/ collaborative-process/, last access: 17 May 2021). This artscience research collaboration brought together artists - 


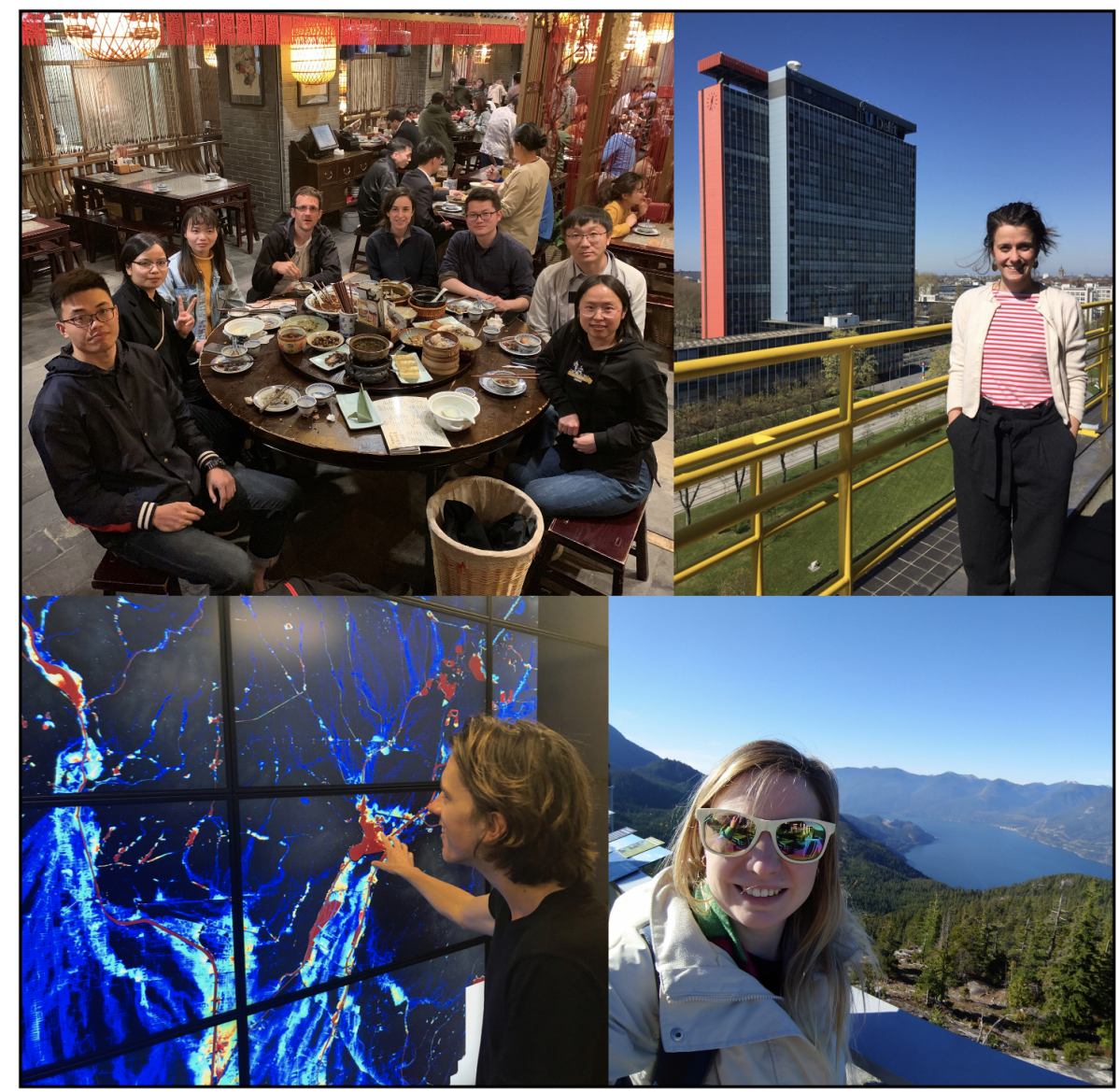

Figure 5. Clockwise from top left: Anna Lo Jacomo (Cohort 2) and Richard Rees (Cohort 3) enjoying the hospitality of their hosts at Hohai University, Nanjing, China; Cohort 2 student Olivia Bailey's research base at TU Delft, Netherlands; Cohort 2 student Olivia MiltonThompson making the most of her research visit to UBC, Vancouver, Canada; and Cohort 2 student Joe Shuttleworth at the University of California, Irvine, USA.

working on environmental issues - and WISE CDT PhD candidates (Fig. 6). The project explored the unstable relationship between society, water and place by exploring flood impacts over the Somerset Levels, a very flood prone region in England. Pairs of one artist and three $\mathrm{PhD}$ candidates jointly developed art pieces, including paintings and drawings, which were subsequently exhibited in a public gallery in Exeter.

The project started with a series of workshops. First, the $\mathrm{PhD}$ candidates came together to gather background knowledge regarding the history and future of flooding over the Somerset Levels. They worked in small groups of three candidates who integrated their findings in a poster so that what they learned was shared with the rest of the group. In a subsequent workshop, candidates and artists were brought together to explain their respective background and interests. Interestingly, it became clear during pre-workshop discussions that both groups were rather nervous about the event. The candidates thought that the artists would consider them to be boring, while the artists assumed that the candidates would think of them as strange. It turned out that both groups actually appreciated the very different viewpoints that the other group presented - challenging their existing mindset. The second workshop included pairing artists and candidates in small groups, which would then go on to develop individual art projects. The small groups self-organised to develop their projects in the outdoors or in the artists' studios. An interesting challenge for the candidates was to produce outcomes, such as a painting, which, in contrast to a scientific graph, did not have a single specific message but rather would trigger different emotions in the audience. The candidates have been trained to ensure that 100 viewers of their graphs would walk away with a single message, while the artists wanted them to (preferably) walk away with 100 different emotions and ideas.

The outcomes of this collaboration were ultimately exhibited publicly in a dedicated gallery space in Exeter, UK. Art pieces included paintings and stone masonry, as well as flood survival kits (including sponges, sand, inflatable rubber and information material) which were handed out to the public in 
Table 2. Research visit locations.

\begin{tabular}{|c|c|}
\hline Institution hosting research visit & Host institution supervisor \\
\hline Asian Institute of Technology, Bangkok, Thailand & Prof. Mukand Babel \\
\hline Centre of Ecology and Hydrology, Wallingford, UK & Dr. Cecilia Svensson \\
\hline University of Saskatchewan, Canmore, Canada & Prof. Martyn Clark \\
\hline Cornell University, Ithaca, USA & Prof. Patrick Reed \\
\hline Delft University of Technology, Delft, the Netherlands & Prof. Jan Peter van der Hoek \\
\hline Deltares/Delft Technical University, the Netherlands & Dr. Robert McCall \\
\hline DHI, Hørsholm, Denmark & Dr. Ole Mark \\
\hline University of British Columbia, Vancouver, Canada & Dr. Aaron Cahill \\
\hline Griffith University, Gold Coast, Australia & Prof. Rodger Tomlinson \\
\hline Ludwig-Franzius-Institut, Leibniz Universität Hannover/Technical University of Braunschweig, Hanover, Germany & Dr. Stefan Schimmels \\
\hline Hohai University, Nanjing, China & Prof. Yongping Chen \\
\hline International Institute for Applied Systems Analysis (IIASA), Laxenburg, Austria & Dr. Yoshihide Wada \\
\hline JBA Consulting & Ms. Kirsty Styles \\
\hline KWR Water Research Institute, Utrecht, Netherlands & Dr. Mirjam Blokker \\
\hline Kyoto University, Kyoto, Japan & Prof. Yasuto Tachikawa \\
\hline Laval University, Quebec, Canada & Prof. Sebastien Houde \\
\hline Leibniz University Hannover, Germany & Dr. Stefan Schimmels \\
\hline Luxembourg Institute of Science and Technology, Luxembourg & Dr. Stan Schymanski \\
\hline Nanjing Normal University/Hohai University, Nanjing, China & Drs. Qiang Dai and Jing Huang \\
\hline National University of Science and Technology, Zimbabwe & Dr. Eugine Makaya \\
\hline National University of Singapore (NUS), Singapore & Prof. Vladan Babovic \\
\hline San Diego State University, USA & Prof. Hilary McMillan \\
\hline Singapore Centre for Environmental Life Sciences and Engineering (SCELSE), Singapore & Dr. Jamie Hinks \\
\hline Hohai University, Nanjing, China & Prof. Pei Xin \\
\hline Stellenbosch University, Stellenbosch, South Africa & Dr. Wesaal Khan \\
\hline Texas A \& M University, College Station, USA & Prof. Scott Socolofsky \\
\hline The University of Auckland, Auckland, New Zealand & Dr. Heide Friedrich \\
\hline Tsinghua University, Beijing, China & Prof. Binliang Lin \\
\hline University College London, UK & Dr. Eugeny Buldakov \\
\hline University of Arizona, USA & Prof. Tom Meixner \\
\hline University of Bologna, Bologna, Italy & Prof. Alberto Montanari \\
\hline University of California, Irvine, California, USA & Prof. Brett Sanders \\
\hline University of Canterbury, Christchurch, New Zealand & Prof. Roger Nokes \\
\hline University of Melbourne, Melbourne, Australia & Prof. Tim Fletcher \\
\hline University of Melbourne, Melbourne, Australia & Dr. Murray Peel \\
\hline University of Waterloo, Waterloo, Ontario, Canada & Prof. Bryan Tolson \\
\hline University of Zurich (UZH), Zurich, Switzerland & Prof. Jan Seibert \\
\hline Washington State Department of Ecology, USA & Dr. George Kaminsky \\
\hline WaterHarvest, India & Om Prakash Sharma \\
\hline University of New South Wales, Sydney, Australia & Prof. Ian Turner \\
\hline Wuhan University, Wuhan, China & Prof. Junqiang Xia \\
\hline
\end{tabular}

Somerset as a starting point for discussion on flooding problems in the area (Fig. 6).

\section{WISE CDT candidates' backgrounds and follow-on careers}

We have recruited a total of five candidate cohorts into the WISE CDT programme (Fig. 2). Each cohort included between 15 and $18 \mathrm{PhD}$ candidates. In total we recruited 84 candidates, of which $39 \%$ were female and $61 \%$ male. Candidates' ages on entry ranged from 21 to 50, with $82 \%$ of candidates being aged between 20-29 at the start of the programme, $17 \%$ aged between $30-39$ and $1 \%$ aged $40+$. Due to the mix of funding through EPSRC, industry and the four participating universities, we were able to recruit both UK (60\%) and EU (40\%) candidates into the programme. We used industry and matching university funding to support EU candidates, since EPSRC funding could only be used to support UK candidates. EU candidates originated from Belgium, Denmark, France, Germany, Greece, Italy, Netherlands, Slovenia and Spain. Most candidates entered the programme after finishing a postgraduate master's degree, while a few had either concluded a 4-year undergraduate programme (e.g. MEng) or a bachelor's degree only. As noted previously, we recruited candidates from a wide range of science and engineering backgrounds as intended, given our goal to provide a broad-based interdisciplinary research programme (Fig. 7).

A relatively small fraction of the candidates have graduated thus far (mainly from cohorts 1 and 2), and any assess- 


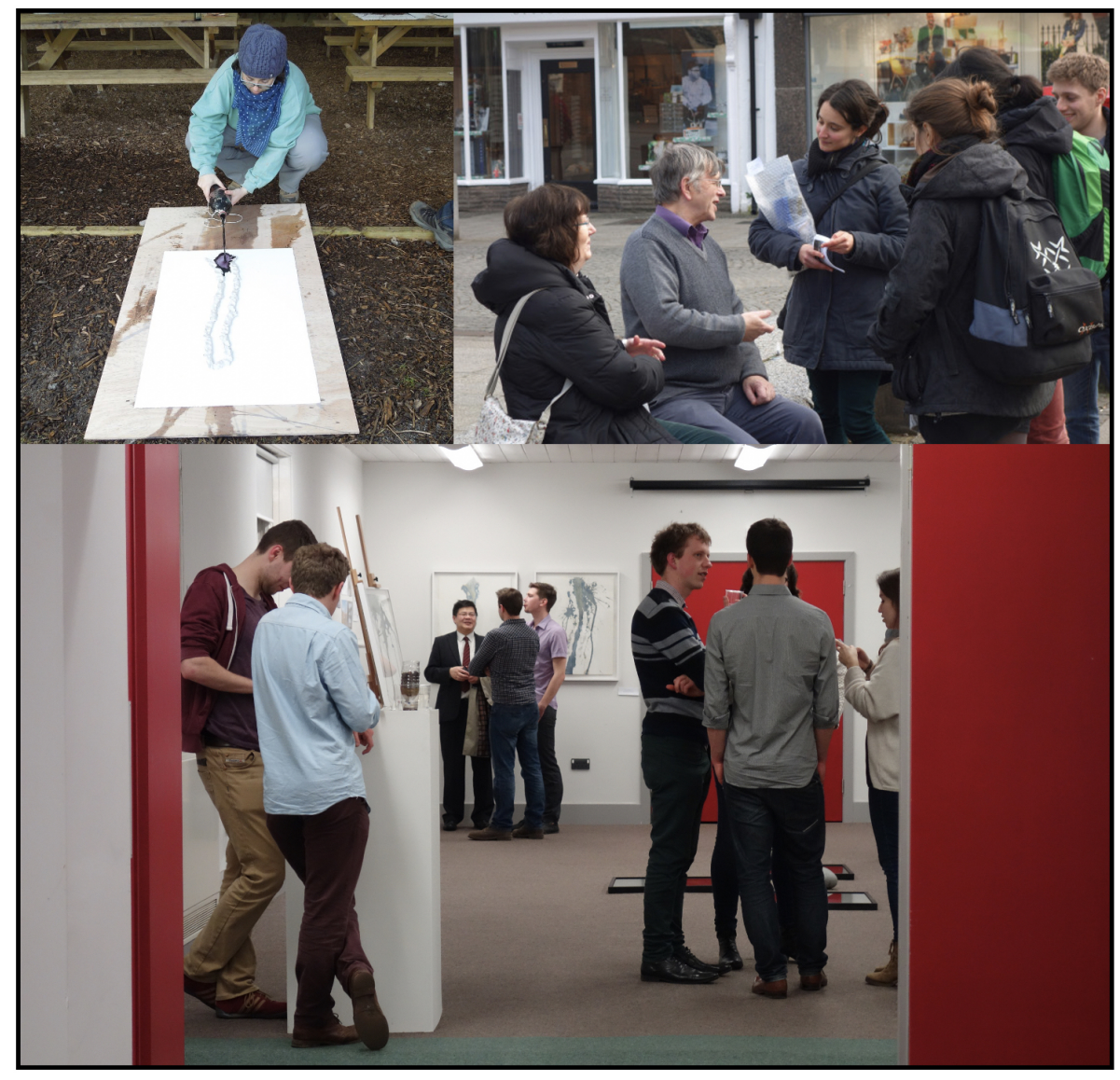

Figure 6. The Land of the Summer People art project paired each group of three $\mathrm{PhD}$ students with an artist. Each group independently developed a piece of art. Pieces included paintings, stone masonry and flood survival kits to be handed out to the public (photo credits: (C) Seila Fernandez Arconada 2014).

ment of the candidates' subsequent career path is therefore preliminary. Experience in other doctoral programmes suggests that strong interactions amongst researchers during the $\mathrm{PhD}$ continue to influence their later career paths (Carr et al., 2017, 2018). It will be interesting to see whether such findings are also true for the WISE CDT programme. The first group of graduating WISE PhD candidates moved into research positions, consultancy and other jobs, such as with the regulatory authorities. For example, Josh Myrans (Cohort 1) extended his $\mathrm{PhD}$ work to further develop artificialintelligence-based technology for automated detection of faults in wastewater pipes from CCTV inspections. This technology, developed initially as part of his WISE PhD, is currently being implemented via a knowledge transfer project with a large UK water company. Maria Xenochristou (Cohort 2) is now employed as a postdoc at Stanford University in the USA. She is using the advanced machine learning and other skills gained during her WISE PhD to advance research in the field of bioinformatics. Rosanna Lane (Cohort 2) now works for the UK Centre for Ecology and Hydrology (UKCEH) in Wallingford, as a hydrological mod- eller - building on the UK-scale modelling framework she developed and tested, while Mariano Marinari (Cohort 1) is a technical consultant for EcoNomad Solutions Ltd and also teaches applied mathematics at a secondary school in his home country of Italy.

\section{Conclusions and lessons learned}

Harnessing and exploiting the rapidly growing sources of available data and computational power are among the greatest professional challenges and opportunities facing water and environmental practitioners as well as researchers today. The proliferation of sensors of various types, large-scale and widespread data acquisition, increasingly sophisticated modelling tools, information and communication technologies, the internet of things, and the roll-out of 5G wireless networks will enable far more symbiotic relationships to be developed between rural populations, city governments, urban citizens and businesses. In the long term, digital sensors, smart phones and wearable smart devices will together form the primary interface between customers, other stakeholders 


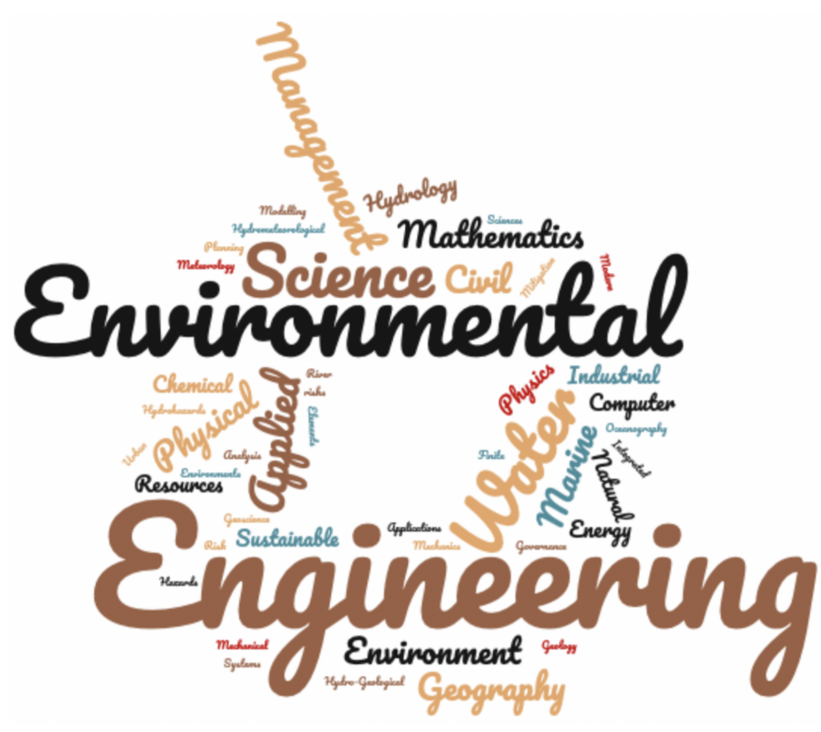

Figure 7. Word cloud indicating the subject areas in which WISE CDT students had obtained their highest entry qualification before entry to the programme.

and the companies providing water services. Massive growth in the availability of open water data enables a strategy to monitor, understand and simulate our non-stationary water environment in new and exciting ways.

The EPSRC Water Informatics in Science and Engineering (WISE) Centre for Doctoral Training (CDT) is an educational response to these opportunities. We use an educational model in which 1 year of initial cohort-based training in one location is followed by 3 years of subsequent research across all partner institutions. Lina Stein (Cohort 3) comments on the cohort benefits of the WISE CDT: "In the cohort there is a wide array of experiences and problem-solving approaches. This creates an atmosphere of mutual help and a tight-knit group of friends. The close contact will hopefully persist in future years, spanning a research network over four universities." Graduated candidates have moved successfully into industrial, practitioner and academic positions. For example, David Evans, director of Natural Energy Wyre, praised the WISE CDT skills development: "The WISE CDT provides a unique opportunity for candidates to participate in shaping their own research topic. This, coupled with the wide range of skills they will acquire by completing all that the postgraduate school offers, makes them very attractive prospective recruits for the Water industry." In addition, the WISE CDT places a strong emphasis on building a bridge between academia and the water industry through the programme. We initially built on existing links between individual academics and companies but expanded these throughout via dedicated activities such as an annual industry day and a very active strategic advisory board. We believe that the $\mathrm{PhD}$ projects (full list on http://wisecdt.org.uk, last access: 17 May 2021) reflect the ambitious goals of the
WISE CDT. Example projects of those candidates who have graduated thus far include "Water demand forecasting using machine learning on weather and smart metering data", "National-scale hydrological modelling of high flows across Great Britain", "Self-powered biosensors for water quality monitoring: sensor development and signal treatment" and "Event Management and Event Response Planning for Smart Water Networks". Several PhD projects were extended as knowledge transfer activities having secured additional funding.

Like any comparable large-scale education programme (Blöschl et al., 2012; Serlet et al., 2020), we experienced successes and challenges along the way, which we have tried to share in this document. We realised that bringing a very heterogeneous group of $\mathrm{PhD}$ candidates together to study requires effort in ensuring that some candidates are not overwhelmed because their background is less quantitative. We also realised that even a seemingly homogeneous $\mathrm{PhD}$ training set-up across four UK universities (as it might look like from outside the UK) reveals significant differences in the approaches taken by individual universities when tested. Solutions to such challenges are transparency and open communication channels for the $\mathrm{PhD}$ candidates to be able (and to feel confident) to highlight problems when they occur. Throughout the programme, we increased $\mathrm{PhD}$ candidate participation in tailoring the programme. Overall, the WISE CDT also certainly represented a tremendous opportunity for the academics involved. We created new research partnerships (within and across universities), and we enjoyed having a large group of excellent junior researchers with the freedom to jointly define research projects with their supervisors without constraints.

We believe that some of our experiences might be helpful for $\mathrm{PhD}$-level water education more widely, outside of dedicated doctoral programmes. In line with the suggestion of one reviewer we list what we believe are some must-haves of modern doctoral training based on our experience.

- We believe that a coordinated baseline training component at the beginning of a $\mathrm{PhD}$ is highly beneficial for most candidates. Training in skills like advanced maths, programming, data analytics and similar knowledge is especially useful and best gained through a coordinated training effort rather than through individual activity. Programmes where such training is common, e.g. in the USA, have an advantage over those that traditionally do not offer a training element (e.g. traditional PhD education in the UK).

- All candidates strongly emphasised that the cohort aspect of our $\mathrm{PhD}$ was a major positive during their $\mathrm{PhD}$ journey. While it will not always be possible to create cohort-based training, our experience nonetheless suggests that coordinated efforts to connect the $\mathrm{PhD}$ candidates that start within a particular time period will be highly beneficial for those involved. 
- Tailored skills training throughout is valuable to help $\mathrm{PhD}$ candidates gain the experience needed for writing, presenting, etc. Candidates throughout the course found such training most helpful when it was tailored to their discipline and specific needs, as well as when it offered wider discussion with experienced academics as part of the training.

The central outcome of the WISE CDT so far is a group of highly trained doctoral candidates and graduates who have been educated in a training environment that was redesigned from the ground up, bringing the strengths of four researchintensive universities together for the first time. Our training programme reaches across traditional science and engineering divisions, in line with the skills that future graduates in this area will need. The programme explicitly acknowledges and encourages interdisciplinary collaborations. To provide an enhanced candidate experience we have invested additional time and resources into transferable skills training and built cohorts of candidates - giving them their first professional networks and even lifelong friends. This redesigned educational experience is our response to modern industry requirements, for example the urgent need to elevate coding skills in training water practitioners, and to the rapidly expanding opportunities in research. Where exactly the best mix between computing skills and water science and engineering knowledge lies continues to be a topic of ongoing debate (Hut et al., 2017), and no doubt the requirements of training programmes such as the WISE CDT will continue to evolve to meet pressing new challenges, from monitoring of biomarkers for new diseases to water security, in the future.

Data availability. There are no data involved in the work presented here beyond those that are included as tables.

Author contributions. TW, DS, DB and DF prepared the draft manuscript. All authors contributed to the final version of the manuscript.

Competing interests. The authors declare that they have no conflict of interest.

Acknowledgements. We gratefully acknowledge additional funding and support from our many academic and industry partners. We thank Alyssa Serlet and the anonymous reviewer for their constructive criticism that helped to improve the paper.

Financial support. The WISE CDT is funded by the Engineering and Physical Sciences Research Council (EPSRC), grant number EP/L016214/1, and by the universities of Bath, Bristol, Cardiff and Exeter.
Review statement. This paper was edited by Daniel Viviroli and reviewed by Alyssa Serlet and one anonymous referee.

\section{References}

Ali, A. and Kohun, F.: Dealing with Social Isolation to Minimize Doctoral Attrition - A Four Stage Framework, Int. J. Doct. Stud., 2, 33-49, 2007.

Blöschl, G., Carr, G., Bucher, C., Farnleitner, A. H., Rechberger, H., Wagner, W., and Zessner, M.: Promoting interdisciplinary education - the Vienna Doctoral Programme on Water Resource Systems, Hydrol. Earth Syst. Sci., 16, 457-472, https://doi.org/10.5194/hess-16-457-2012, 2012.

Brodin, E. M. and Avery, H.: Cross-Disciplinary Collaboration and Scholarly Independence in Multidisciplinary Learning Environments at Doctoral Level and Beyond, Minerva, 58, 409-433, https://doi.org/10.1007/s11024-020-09397-3, 2020.

Brown, C. M., Lund, J. R., Cai, X., Reed, P. M., Zagona, E. A., Ostfeld, A., Hall, J., Characklis, G. W., Yu, W., and Brekke, L.: The future of water resources systems analysis: Toward a scientific framework for sustainable water management, Water Resour. Res., 51, 6110-6124, https://doi.org/10.1002/2015WR017114, 2015.

Buckley, F., Brogan, J., Flynn, J., Monks, K., Hogan, T., and Alexopoulos, A.: Doctoral competencies and graduate research education: focus and fit with the knowledge economy?, Link Working Paper Series, DCU Business School, Dublin, Ireland, 2009.

Carr, G., Blanch, A. R., Blaschke, A. P., Brouwer, R., Bucher, C., Farnleitner, A. H., Fürnkrantz-Prskawetz, A., Loucks, D. P., Morgenroth, E., Parajka, J., Pfeifer, N., Rechberger, H., Wagner, W., Zessner, M., and Blöschl, G.: Emerging outcomes from a crossdisciplinary doctoral programme on water resource systems, Water Policy, 19, 463-478, https://doi.org/10.2166/wp.2017.054, 2017.

Carr, G., Loucks, D. P., and Blöschl, G.: Gaining insight into interdisciplinary research and education programmes: A framework for evaluation, Res. Policy, 47, 35-48, https://doi.org/10.1016/j.respol.2017.09.010, 2018.

CEDEFOP: Insights into Skill Shortages and Skill Mismatch, Luxembourg, https://doi.org/10.2801/645011, 2018.

Ceola, S. Arheimer, B., Blöschl, G., Baratti, E., Capell, R., Castellarin, A., Freer, J., Han, D., Hrachowitz, M., Hundecha, Y., Hutton, C., Lindström, G., Montanari, A., Nijzink, R., Parajka, J., Toth, E., Viglione, A., and Wagener, T.: Virtual laboratories: New opportunities for collaborative water science, Hydrol. Earth Syst. Sci., 19, 2101-2117, https://doi.org/10.5194/hess-19-2101-2015, 2015.

CIWEM: Water sector employers concerned over engineering skills gap, available at: https://wwtonline.co.uk/news/ water-sector-employers-concerned-over-engineering-skills-gap(last access: August 2020), 2016.

Clark, M. P., Fan, Y., Lawrence, D. M., Adam, J. C., Bolster, D., Gochis, D. J., Hooper, R. P., Kumar, M., Leung, L. R., Mackay, D. S., Maxwell, R. M., Shen, C., Swenson, S. C., and Zeng, X.: Improving the representation of hydrologic processes in Earth System Models, Water Resour. Res., 51, 5929-5956, 2015.

CST - Council for Science and Technology: Improving Innovation in the Water Industry, London, 40 pp., 2009. 
Gleeson, T., Wang-Erlandsson, L., Porkka, M., Zipper, S. C., Jaramillo, F., Gerten, D., Fetzer, I., Cornell, S. E., Piemontese, L., Gordon, L. J., Rockström, J., Oki, T., Sivapalan, M., Wada, Y., Brauman, K. A., Flörke, M., Bierkens, M. F. P., Lehner, B., Keys, P., Kummu, M., Wagener, T., Dadson, S., Troy, T. J., Steffen, W., Falkenmark, M., and Famiglietti, J. S.: Illuminating water cycle modifications and Earth system resilience in the Anthropocene, Water Resour. Res., 56, e2019WR024957, https://doi.org/10.1029/2019WR024957, 2020.

Habib, E., Ma, Y., Williams, D., Sharif, H. O., and Hossain, F.: HydroViz: design and evaluation of a Web-based tool for improving hydrology education, Hydrol. Earth Syst. Sci., 16, 3767-3781, https://doi.org/10.5194/hess-16-3767-2012, 2012.

Hut, R. W., van de Giesen, N. C., and Drost, N.: Comment on "Most computational hydrology is not reproducible, so is it really science?" by Christopher Hutton et al.: Let hydrologists learn the latest computer science, Water Resour. Res., 53, 4524-4526, 2017.

ICE - Institution of Civil Engineers: The State of the Nation: Water 2012, London, 20 pp., 2012.

ICT4Water cluster: Welcome to the ICT4Water Cluster, available at: https://ict4water.eu (last access: 17 May 2021), 2018.

Jain, S. and Lall, U.: Floods in a changing climate: Does the past represent the future?, Water Resour. Res., 37, 3193-3205, 2001.

Jonker, L., van der Zaag, P., Gumbo, B., Rockström, J., Love, D., and Savenije, H. H. G.: A regional and multi-faceted approach to postgraduate water education - the WaterNet experience in Southern Africa, Hydrol. Earth Syst. Sci., 16, 4225-4232, https://doi.org/10.5194/hess-16-4225-2012, 2012.

King, E. G., O’Donnell, F. C., and Caylor, K. K.: Reframing hydrology education to solve coupled human and environmental problems, Hydrol. Earth Syst. Sci., 16, 4023-4031, https://doi.org/10.5194/hess-16-4023-2012, 2012

Makropoulos, C. and Savić, D. A.: Urban Hydroinformatics: Past, Present and Future, Water, 11, 1959, https://doi.org/10.3390/w11101959, 2019.

Mao, F., Clark, J., Buytaert, W., Krause, S., and Hannah, D. M.: Water sensor network applications: Time to move beyond the technical?, Hydrol. Process., 32, 2612-2615, 2018.

McAlpine, L., Jazvac-Martek, M., and Hopwood, N.: Doctoral student experience in education: activities and difficulties influencing identity development, Int. J. Res. Dev., 1, 97-109, 2009.

Merwade, V. and Ruddell, B. L.: Moving university hydrology education forward with community-based geoinformatics, data and modeling resources, Hydrol. Earth Syst. Sci., 16, 2393-2404, https://doi.org/10.5194/hess-16-2393-2012, 2012.

Milly, P. C. D., Betancourt, J., Falkenmark, M., Hirsch, R. M., Kundzewicz, Z. W., Lettenmaier, D. P., and Stouffer, R. J.: Stationarity is dead: Whither water management?, Science, 319, 573-574, https://doi.org/10.1126/science.1151915, 2008.

Montanari, A., Young, G., Savenije, H., Hughes, D., Wagener, T., Ren, L., Koutsoyiannis, D., Cudennec, C., Grimaldi, S., Bloeschl, G., Sivapalan, M., Beven, K., Gupta, H., Arheimer, B., Huang, Y., Schumann, A., Post, D., Tani, M., Boegh, E., Hubert, P., Harman, C., Thompson, S., Rogger, M., Hipsey, M., Toth, E., Viglione, A., Di Baldassarre, G., Schaefli, B., McMillan, H., Schymanski, S., Characklis, G., Yu, B., Pang, Z., and Belyaev, V.: "Panta Rhei - Everything Flows": Change in hydrology and so- ciety - The IAHS Scientific Decade 2013-2022, Hydrolog. Sci. J., 58, 1256-1275, 2013.

Musolini, G., Ahmadian, R., Xia, J., and Falconer, R. A.: Mapping the danger to life in flash flood events adopting a mechanics based methodology and planning evacuation routes, J. Flood Risk Manage., 13, 12627, https://doi.org/10.1111/jfr3.12627, 2020.

Popescu, I., Jonoski, A., and Bhattacharya, B.: Experiences from online and classroom education in Hydroinformatics, Hydrol. Earth Syst. Sci., 16, 3935-3944, https://doi.org/10.5194/hess-163935-2012, 2012.

RAE - Royal Academy of Engineering: Engineering the Future of Water, $16 \mathrm{pp}$., available at: https://www.raeng.org.uk/publications/reports/ engineering-the-future-of-water-review-of-2011 (last access: 17 May 2021), 2012.

RCUK - Research Councils UK: Review of progress in implementing the recommendations of Sir Gareth Roberts, regarding employability and career development of $\mathrm{PhD}$ students and research staff, available at: https://repository.lboro.ac.uk/articles/report/ Review_of_progress_in_implementing_the_recommendations_ of_Sir_Gareth_Roberts_regarding_employability_and_career_ development_of_PhD_students_and_research_staff/9354350/1 (last access: 17 May 2021), 2010.

Roberts, G.: SET for success: - The supply of people with science, technology, engineering and mathematics skills, The report of Sir Gareth Roberts' Review, UK Government Publication, available at: https://dera.ioe.ac.uk/4511/1/robertsreview_introch1.pdf (last access: 17 May 2021), 2002.

Romano, M., Kapelan, Z., and Savic, D. A.: Automated Detection of Pipe Bursts and other Events in Water Distribution Systems, J. Water Resour. Plan. Manage.-ASCE, 140, 457-467, https://doi.org/10.1061/(ASCE)WR.1943-5452.0000339, 2014.

Rudell, B. L. and Wagener, T.: Grand challenges for engineering hydrology education in the 21 st century, J. Hydrol. Eng.ASCE, 20, A4014001, https://doi.org/10.1061/(ASCE)HE.19435584.0000956, 2013.

Seibert, J., Uhlenbrook, S., and Wagener, T.: Preface: Hydrology education in a changing world, Hydrol. Earth Syst. Sci., 17, 1393-1399, https://doi.org/10.5194/hess-17-1393-2013, 2013.

Seibert, J., Strobl, B., Etter, S., Hummer, P., and van Meerveld, H. J.: Virtual staff gauges for crowdbased stream level observations, Front. Earth Sci., 7, 1-10, https://doi.org/10.3389/feart.2019.00070, 2019.

SENSUS: Water 20/20: Bringing Smart Water Networks into Focus, Raleigh, NC, USA, 40 pp., 2012.

Serlet, A. J., Lopez Moreira, G. A., Zolezzi, G., Wharton, G., Hölker, F., Gurnell, A. M., Trockner, K., Bertoldi, W., Bruno, M. C., Jähnning, S. C., Lewandowski, J., Monaghan, M. T., Rillig, M. C., Rogato, M., Toffolon, M., Veresoglou, S. D., and Zarfl, C.: SMART Research: Toward Interdisciplinary River Science in Europe, Front. Environ. Sci., https://doi.org/10.3389/fenvs.2020.00063, in press, 2020.

Sivapalan, M. and Blöschl, G.: Time scale interactions and the coevolution of humans and water, Water Resour. Res., 51, 69887022, https://doi.org/10.1002/2015WR017896, 2015.

Smart Water Magazine: Bluefield Research key trends in US water market 2020, available at: https: //smartwatermagazine.com/news/bluefield-research/ 
bluefield-research-key-trends-us-water-market-2020, last access: June 2020.

Thompson, S. E., Ngambeki, I., Troch, P. A., Sivapalan, M., and Evangelou, D.: Incorporating student-centered approaches into catchment hydrology teaching: a review and synthesis, Hydrol. Earth Syst. Sci., 16, 3263-3278, https://doi.org/10.5194/hess-163263-2012, 2012.

Uhlenbrook, S. and de Jong, E.: T-shaped competency profile for water professionals of the future, Hydrol. Earth Syst. Sci., 16, 3475-3483, https://doi.org/10.5194/hess-16-3475-2012, 2012.

UNEP - United Nations Environment Programme: Water security and ecosystem services: The critical connection, Nairobi, Kenya, 2009.

UNEP - United Nations Environment Programme: Synthesis of the Key Findings, UK National Ecosystem Assessment, 87 pp., available at: https://www.unep-wcmc.org/resources-anddata/the-uk-national-ecosystem-assessment-synthesis-of-thekey-, findings-and-technical-reports (last access: 17 May 2021), 2011.
UNEP - United Nations Environment Programme: Freshwater strategy 2017-2021, available at: https://wedocs. unep.org/bitstream/handle/20.500.11822/19528/UNEP-full_ report-170502.pdf (last access: 17 May 2021), 2017.

Wagener, T., Sivapalan, M., Troch, P. A., McGlynn, B. L., Harman, C. J., Gupta, H. V., Kumar, P., Rao, P. S. C., Basu, N. B., and Wilson, J. S.: The future of hydrology: An evolving science for a changing world, Water Resour. Res., 46, W05301, https://doi.org/10.1029/2009WR008906, 2010.

Wagener, T., Kelleher, C., Weiler, M., McGlynn, B., Gooseff, M., Marshall, L., Meixner, T., McGuire, Gregg, S., Sharma, P., and Zappe, S.: It takes a community to raise a hydrologist: The Modular Curriculum for Hydrologic Advancement (MOCHA), Hydrol. Earth Syst. Sci., 16, 3405-3418, https://doi.org/10.5194/hess-16-3405-2012, 2012.

Water Europe: The value of water - Multiple waters for multiple purposes and users, available at: https://watereurope.eu/ wp-content/uploads/2020/04/WE-Water-Vision-english_online. pdf, last access: June 2020. 